\title{
Lung-thorax compliance measured during a spontaneous breathing trial is a good index of extubation failure in the surgical intensive care unit: a retrospective cohort study
}

Yugo Okabe ${ }^{1 *}$ (D), Takehiko Asaga', Sayuri Bekku', Hiromi Suzuki ${ }^{2}$, Kanae Kanda ${ }^{3}$, Takeshi Yoda ${ }^{4}$, Tomohiro Hirao $^{3}$ and Gotaro Shirakami ${ }^{1}$

\begin{abstract}
Background: Extubation failure is associated with mortality and morbidity in the intensive care unit. Ventilator weaning protocols have been introduced, and extubation is conducted based on the results of a spontaneous breathing trial. Room for improvement still exists in extubation management, and additional objective indices may improve the safety of the weaning and extubation process. Static lung-thorax compliance reflects lung expansion difficulty that is caused by several conditions, such as atelectasis, fibrosis, and pleural effusion. Nevertheless, it is not used commonly in the weaning and extubation process. In this study, we investigated whether lung-thorax compliance is a good index of extubation failure in adults even when patients pass a spontaneous breathing trial.
\end{abstract}

Methods: In a single-center, retrospective cohort study, patients over 18 years of age were mechanically ventilated, weaned with proportional assist ventilation, and underwent a spontaneous breathing trial process in surgical intensive care units of Kagawa University Hospital from July 2014 to June 2016. Extubation failure was the outcome measure of the study. We defined extubation failures as when patients were reintubated or underwent non-invasive positive-pressure ventilation within $24 \mathrm{~h}$ after extubation. Receiver operating characteristic (ROC) curve analysis was performed to evaluate the clinical involvement of several parameters. The area under the curve (AUC) was calculated to assess the discriminative power of the parameters.

Results: We analyzed 173 patients and compared the success and failure groups. Most patients (162, 93.6\%) were extubated successfully, and extubation failed in 11 patients (6.4\%). The averages of lung-thorax compliance values in the success and failure groups were $71.9 \pm 23.0$ and $43.3 \pm 14.6 \mathrm{~mL} / \mathrm{cmH}_{2} \mathrm{O}$, respectively, and were significantly different $(p<0.0001)$. In the ROC curve analysis, the AUC was highest for lung-thorax compliance $(0.862)$, followed by the respiratory rate $(0.821)$, rapid shallow breathing index (0.781), Acute Physiology and Chronic Health Evaluation II score (0.72), heart rate (0.715), and tidal volume (0.695).

Conclusions: Lung-thorax compliance measured during a spontaneous breathing trial is a potential indicator of extubation failure in postoperative patients.

Keywords: Lung and thorax compliance, Spontaneous breathing trial, Extubation failure, Proportional assist ventilation

\footnotetext{
* Correspondence: m95018@med.kagawa-u.ac.jp

${ }^{1}$ Department of Anesthesiology, Faculty of Medicine, Kagawa University,

1750-1 Ikenobe, Miki-Cho, Kagawa 761-0793, Japan

Full list of author information is available at the end of the article
}

(c) The Author(s). 2018 Open Access This article is distributed under the terms of the Creative Commons Attribution 4.0 International License (http://creativecommons.org/licenses/by/4.0/), which permits unrestricted use, distribution, and reproduction in any medium, provided you give appropriate credit to the original author(s) and the source, provide a link to the Creative Commons license, and indicate if changes were made. The Creative Commons Public Domain Dedication waiver (http://creativecommons.org/publicdomain/zero/1.0/) applies to the data made available in this article, unless otherwise stated. 


\section{Background}

Extubation failure is associated with mortality and morbidity in the intensive care unit (ICU) [1-6]. Ventilator weaning and extubation were previously based on the experience of the intensivist, but in recent years, ventilator weaning protocols have been introduced, and extubation is conducted based on the results of a spontaneous breathing trial (SBT) [7-9]. SBT is a test to determine whether a patient can tolerate the condition without the support of mechanical ventilation. Close observation and objective judgment contribute to shortening mechanical ventilation duration and reducing the reintubation rate [7-9]; however, the reintubation rate is still 11-19\% [1-4, 10-15]. Room for improvement still exists in extubation management, and additional objective indices may increase the safety of the weaning and extubation process.

Static lung-thorax compliance (LTC), which is calculated by the formula: tidal volume $(\mathrm{mL}) /($ pressure measured from the onset of end-inspiratory occlusion - positive end-expiratory pressure) $\left(\mathrm{cmH}_{2} \mathrm{O}\right)$ [16-18], is a candidate for an index that can help to more safely extubate patients. LTC reflects the difficulty of lung expansion that is caused by several conditions such as atelectasis, fibrosis, pleural effusion, intrapulmonary fluid retention, or a decrease in compliance due to obesity [17-19]. Monitoring LTC is useful because intensivists can evaluate the conditions of the lung and respiratory muscles [20, 21]. However, LTC is not commonly used in the weaning and extubation process because the measurement of LTC under spontaneous breathing is possible only under proportional assist ventilation
(PAV) [16]. Thus, the relationship between LTC during spontaneous breathing and extubation failure is not clear.

PAV is a mode that assists ventilation in proportion to the instantaneous effort of the patient's breathing [22]. In this mode, LTC can be measured with less stress for the patients [16]. Because PAV is superior to pressure support ventilation (PSV), which is synchronized with spontaneous breathing [23-25], intensivists can reduce sedative use [26] and judge an SBT more precisely [27-29]. In this study, we investigated whether LTC is a good index of extubation failure among adults who passed the SBT.

\section{Methods \\ Study population}

We conducted a single-center, retrospective cohort study involving patients over 18 years of age who were admitted to the surgical intensive care unit (SICU) in Kagawa University Hospital from July 2014 to June 2016. Patients who were ventilated mechanically, weaned with PAV, and underwent a SBT process were included in the analysis. The following patients were excluded because the SBT process was not conducted: patients who had disorders in their central nervous system, patients who died before extubation, patients who underwent a tracheotomy before SICU admission, patients who were extubated accidentally, and patients with a good postoperative condition who were extubated without SBT (Fast track extubation). In addition, patients who were subjected to ventilation modes other than PAV for staff education were also excluded (Fig. 1).

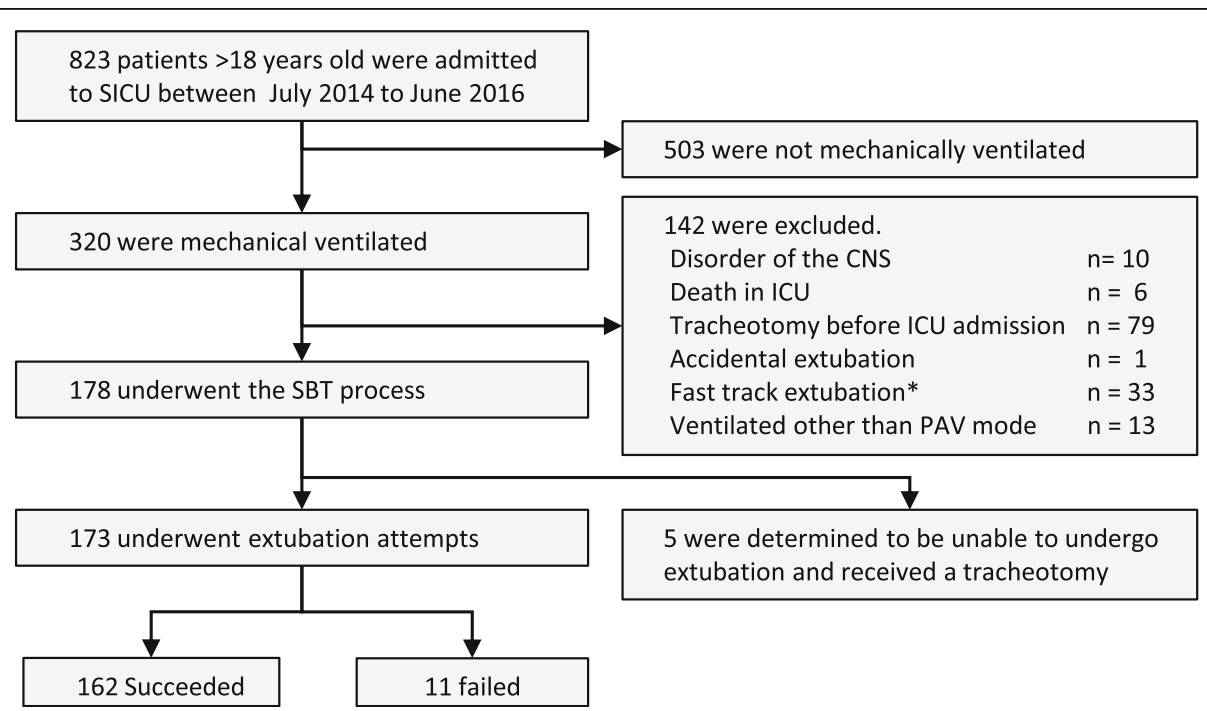

Fig. 1 Number of patients included and excluded from the study. A total of 823 patients older than 18 years of age were admitted to the SICU. Among them, 503 patients were not mechanically ventilated during the SICU stay. According to the exclusion criteria, 142 patients were excluded. A total of 178 patients underwent the SBT process; however, 5 patients underwent a tracheotomy. Finally, we analyzed 173 patients and compared the success and failure groups. Most patients (162,93.6\%) were extubated successfully, and 11 (6.4\%) failed the extubation. *Fast track extubation: extubation without SBT for patients with good postoperative condition; SICU: surgical intensive care unit; CNS: central nervous system; ICU: intensive care unit; PAV: proportional assist ventilation; SBT: spontaneous breathing trial 


\section{SBT process}

Intensivists assessed the spontaneous breathing ability of the patient before starting the SBT process (Fig. 2). The ventilation mode was changed to synchronized intermittent mandatory ventilation (SIMV) at the time of ICU admission. We used propofol and dexmedetomidine hydrochloride for sedation and maintained the Richmond Agitation-Sedation Scale (RASS) between - 3 and -1 [30]. We also used a continuous infusion of fentanyl 10-100 $\mathrm{mcg} / \mathrm{h}$, peripheral nerve block (PNB), epidural anesthesia, and nonsteroidal anti-inflammatory drugs (NSAIDs) for analgesia. When the patient exhibited spontaneous breathing of ten times per minute or more, PAV was initiated. We adjusted the support rate (15-30\%) so that the patient's work of breathing (WOB) was maintained in a comfortable range $(0.3-0.7 \mathrm{~J} / \mathrm{L})$. Under close observation and when the patient met the entry criteria (Table 1), sedative drugs were reduced until the RASS was -2 to 0 . Intensivists observed the patient for 30-60 $\mathrm{min}$ [31] and determined whether to extubate when the patient met the extubation criteria (Table 1) [32]. If patients did not meet the criteria, PAV was continued, and ICU members, including intensivists, attending physicians, anesthesiologists, and ICU nurses, discussed whether to wait until the patient's status improved or a tracheotomy was performed [33]. The PB 840 ventilator (Covidien, USA) was employed to apply the PAV mode for patients. After extubation, all patients were given a high-flow nasal cannula (HFNC) or oxygen mask. If the patient failed to maintain with HFNC, we decided whether to use non-invasive positive-pressure ventilation (NPPV) or reintubate.

\section{Outcome and parameters}

Extubation failure was the outcome measure of the study. We defined extubation failure as when patients were reintubated or when NPPV was conducted within $24 \mathrm{~h}$ after extubation. As potential factors influencing the outcome, sex, age, body mass index (BMI) at admission, type of surgery, emergency surgery, ventilation period, number of SBT, use of HFNC and NPPV, and Acute Physiology and Chronic Health Evaluation II (APACHE II) scores [34] at SICU entrance were collected through the electronic medical record. Parameters that can be monitored during the weaning process, such as the heart rate (HR), respiratory rate (RR), tidal volume (TV), rapid shallow breathing index (RSBI), positive end-expiratory pressure (PEEP), arterial oxygen saturation $\left(\mathrm{SpO}_{2}\right)$, end-tidal carbon dioxide $\left(\mathrm{EtCO}_{2}\right), \mathrm{WOB}$, and LTC were also extracted afterward from an ICU electronic medical record system, RPM-7400 (Nihon Koden, Tokyo, Japan). All parameters were measured each minute, and the average of the last $30 \mathrm{~min}$ of the observation period was recorded.

\section{Statistical analysis}

We calculated that a minimum of eight patients in each group would be required to have $80 \%$ power to detect a difference in LTC of $30 \mathrm{~mL} / \mathrm{cmH}_{2} \mathrm{O}$ between the success and failure groups at a significance level of 0.05 . In the literature, the LTC in healthy adults is $80-100 \mathrm{~mL} /$ $\mathrm{cmH}_{2} \mathrm{O}$ [35], and in acute respiratory distress syndrome (ARDS) or cardiogenic pulmonary edema, the LTC is 29-42 $\mathrm{mL} / \mathrm{cmH}_{2} \mathrm{O}$ [35-37]. The standard deviations of the LTC are reported to be $7-13 \mathrm{~mL} / \mathrm{cmH}_{2} \mathrm{O}[36,37]$.

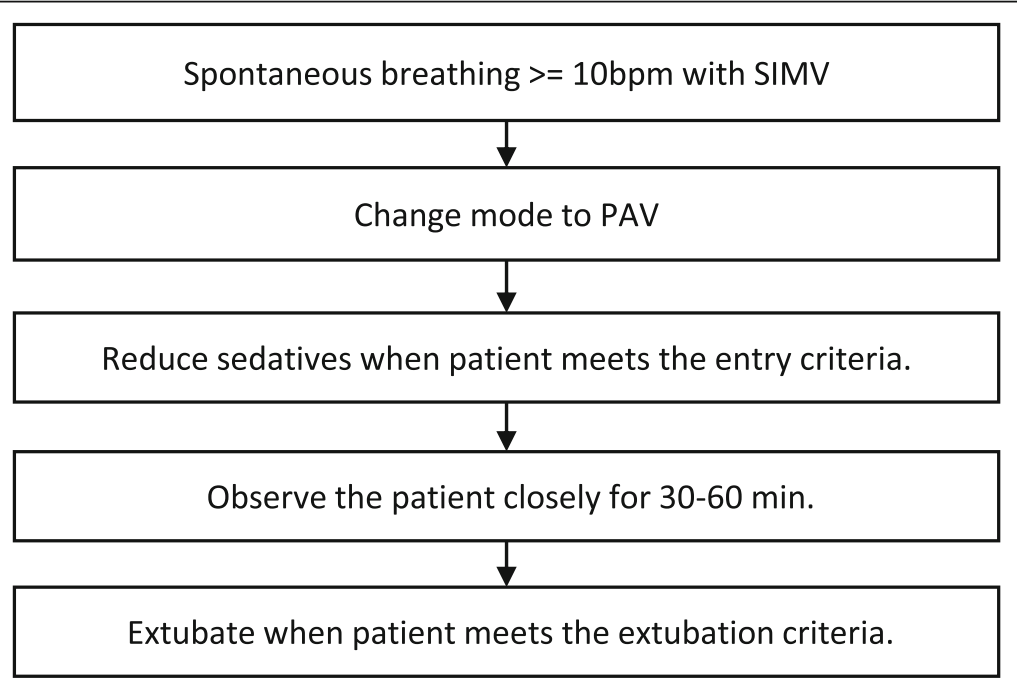

Fig. 2 Flowchart of the SBT process. Intensivists assessed the spontaneous breathing ability of the patient before the SBT process. When the patient exhibited spontaneous breathing of 10 times per minute or more, PAV was initiated. Under close observation and when the patient met the entry criteria, sedative drugs were reduced until the RASS was -2 to 0 . Intensivists observed the patient for 30-60 min and determined whether to extubate when the patient met the extubation criteria. SIMV: synchronized intermittent mandatory ventilation; PAV: proportional assist ventilation; SBT: spontaneous breathing trial 
Table 1 Criteria for the SBT process

\begin{tabular}{|c|c|}
\hline \multicolumn{2}{|l|}{ Entry criteria } \\
\hline $\mathrm{SpO}_{2}$ & $\begin{array}{l}\geq 94 \% \text { with } \mathrm{FiO}_{2} \leq 0.5, \mathrm{PEEP} \leq 7 \mathrm{cmH}_{2} \mathrm{O} \\
\text { support of } \mathrm{WOB} \leq 40 \%\end{array}$ \\
\hline $\mathrm{PaO}_{2}$ & $\geq 70 \mathrm{mmHg}$ \\
\hline Respiratory acidosis & No acidosis \\
\hline Heart rate & $\leq 120 \mathrm{bpm}$ \\
\hline Dopamine & $\leq 5 \mathrm{mcg} / \mathrm{kg} / \mathrm{min}$ \\
\hline Dobutamine & $\leq 5 \mathrm{mcg} / \mathrm{kg} / \mathrm{min}$ \\
\hline Noradrenaline & $\leq 0.05 \mathrm{mcg} / \mathrm{kg} / \mathrm{min}$ \\
\hline Hemoglobin & $\geq 8 \mathrm{~g} / \mathrm{dl}$ \\
\hline Electrolyte abnormality & No abnormality \\
\hline \multicolumn{2}{|l|}{ Extubation criteria } \\
\hline \multicolumn{2}{|l|}{ Consciousness } \\
\hline $\begin{array}{l}\text { Richmond Agitation- } \\
\text { Sedation Scale }\end{array}$ & -2 to 0 \\
\hline $\begin{array}{l}\text { Confusion assessment } \\
\text { method for the ICU }\end{array}$ & Negative \\
\hline \multicolumn{2}{|l|}{ Respiration } \\
\hline Respiratory rate & $\leq 30 / \min$ \\
\hline $\mathrm{RSBI}$ & $<105$ \\
\hline Labored breathing & No \\
\hline Increased WOB & No \\
\hline \multicolumn{2}{|l|}{ Gas exchange } \\
\hline $\mathrm{SpO}_{2}$ & $\geq 94 \%$ \\
\hline $\mathrm{PaO}_{2}$ & $\geq 70 \mathrm{mmHg}$ \\
\hline $\mathrm{pH}$ & $\geq 7.32$ \\
\hline $\mathrm{PaCO}_{2}$ & $\leq 45 \mathrm{mmHg}$ \\
\hline \multicolumn{2}{|l|}{ Circulation } \\
\hline Heart rate & $\leq 120 / \mathrm{min}$ \\
\hline Systolic blood pressure & 80 to $180 \mathrm{mmHg}$ \\
\hline
\end{tabular}

SBT spontaneous breathing trial, $\mathrm{FiO}_{2}$ inspired oxygen fraction, PEEP positive end-expiratory pressure, $W O B$ work of breathing, $\mathrm{SpO}_{2}$ arterial oxygen saturation, $\mathrm{PaO}_{2}$ partial pressure of arterial oxygen, $R S B \mathrm{~B}$ rapid shallow breathing index, $\mathrm{PaCO}_{2}$ partial pressure of arterial carbon dioxide

Because LTC data for target patients were not available, we used a difference of $30 \mathrm{~mL} / \mathrm{cmH}_{2} \mathrm{O}$. Categorical data were analyzed using Fisher's exact test. For the other parameters, a Mann-Whitney $U$ test was used to compare the success and failure groups. Receiver operating characteristic (ROC) curve analysis was performed to evaluate the clinical implications of parameters. The area under the curve (AUC) was calculated to assess the discriminative power of the parameters. The analysis was performed using JMP Pro version 13.2.1 (SAS Institute Inc., Cary, NC, USA). This study was approved by the Ethical Review Board, Faculty of Medicine, Kagawa University (Heisei 29-049). The authors have no conflicts of interest to declare.

\section{Results}

A total of 823 patients older than 18 years of age were admitted to the SICU during the target period. Among them, 503 patients were not mechanically ventilated during the SICU stay. According to the exclusion criteria, 142 patients were excluded. A total of 178 patients underwent the SBT process; however, 5 patients underwent a tracheotomy because they were judged to be unable to meet the extubation criteria by ICU members. Finally, we analyzed 173 patients and compared the success and failure groups. No patient had serious respiratory illness before the surgery or at ICU admission.

The subjects consisted of $65.9 \%$ men and $34.1 \%$ women, with a mean age of 68.2 years. Most (98.3\%) were surgical patients, 90 (52.0\%) were cardiac patients, 34 (19.7\%) were craniocervical patients, and 16 (9.2\%) were gastrointestinal surgery patients. Most patients (162, 93.6\%) were extubated successfully, and 11 (6.4\%) failed the extubation. In the failure group, three (27.3\%) patients used NPPV, and eight (72.3\%) were reintubated (Table 2). Four patients failed due to sputum clogging, three had pulmonary edema, two had hypercapnia, and one had aspiration pneumonia, and another was hypoxemic. The ventilation period and SBT number were $1651 \pm 3011$ min (mean \pm SD) and $1 \pm 1.7$ (median \pm SD) in the success group and $2330 \pm 3797 \mathrm{~min}$ and $2 \pm 2.9$ in the failure group, respectively. There was no difference between the groups. Only vascular surgery and WOB were significantly associated with extubation failure (Table 2). The mean age and sex ratio was not different between the two groups. Among patient parameters, the APACHE II score, HR, RR, TV, RSBI, and LTC were significantly different. The average LTC values in the success and failure groups were $71.9 \pm 23.0$ and $43.3 \pm 14.6$, respectively, which were significantly different $(p<0.0001)$ (Table 3).

In the ROC curve analysis, the AUC was highest for LTC (0.862), followed by the RR (0.821), RSBI (0.781), APACHE II score (0.720), HR (0.715), and TV (0.695) (Fig. 3).

\section{Discussion}

LTC measured during the SBT was highly associated with extubation failure. The AUC of LTC was 0.862 , which was highest among the parameters; therefore, LTC may be a good predictor of extubation failure. We compared the sensitivity and specificity of each parameter at the highest value of the Youden index [38], which was defined by the following formula: (sensitivity + specificity -1). The maximum value of the Youden index was used as a criterion for selecting the optimum cutoff point of diagnostic tests [38]. At a cutoff point of 54, LTC had a moderate degree of sensitivity and a high degree of specificity. Considering patient safety, higher 
Table 2 Subject backgrounds

\begin{tabular}{|c|c|c|c|c|}
\hline & Total & Success & Failure & $p$ value \\
\hline & $n=173$ & $n=162$ & $n=11$ & \\
\hline \multicolumn{5}{|l|}{ Sex, $n(\%)$} \\
\hline Male & $114(65.9)$ & $107(66.1)$ & $7(63.6)$ & 0.553 \\
\hline Female & $59(34.1)$ & $55(34.0)$ & $4(36.4)$ & 0.696 \\
\hline Age $($ mean $\pm S D)$ & $68.2 \pm 12.8$ & $68.2 \pm 12.9$ & $69.3 \pm 11.7$ & 0.854 \\
\hline Surgery, $n(\%)$ & $170(98.3)$ & $160(98.8)$ & $10(90.9)$ & 0.179 \\
\hline Cardiac & $90(52.0)$ & $86(53.1)$ & $4(36.4)$ & 0.519 \\
\hline Craniocervical & $34(19.7)$ & $34(21.0)$ & $0(0.0)$ & 0.215 \\
\hline Gastrointestinal & $16(9.2)$ & $13(8.0)$ & $3(27.3)$ & 0.064 \\
\hline Vascular & $14(8.1)$ & $11(6.8)$ & $3(27.3)$ & 0.031 \\
\hline Other surgery & $16(9.2)$ & $16(9.9)$ & $0(0.0)$ & 0.601 \\
\hline Others, $n(\%)$ & $3(1.7)$ & $2(1.2)$ & $1(9.1)$ & 0.989 \\
\hline Emergency surgery, $n$ (\%) & $14(8.1)$ & $13(8.0)$ & $1(9.1)$ & 0.616 \\
\hline Ventilation period, min (mean $\pm S D)$ & $1694 \pm 3058$ & $1651 \pm 3011$ & $2330 \pm 3797$ & 0.516 \\
\hline SBT times (median \pm SD) & $1 \pm 1.8$ & $1 \pm 1.7$ & $2 \pm 2.9$ & 0.158 \\
\hline$W B^{*}, J / L($ mean $\pm S D)$ & $0.77 \pm 0.27$ & $0.76 \pm 0.26$ & $0.99 \pm 0.41$ & 0.015 \\
\hline HFNC, $n(\%)$ & $123(71.1)$ & $112(69.1)$ & $11(100)$ & 0.026 \\
\hline NPPV, $n(\%)$ & $3(1.7)$ & $0(0.0)$ & $3(27.3)$ & 0.0002 \\
\hline
\end{tabular}

The Mann-Whitney $U$ test and Fischer's exact test were applied. *WOB is a calculated estimate

$S B T$ spontaneous breathing trial, WOB work of breathing, HFNC high-flow nasal cannula, NPPV non-invasive positive-pressure ventilation

Table 3 Comparison of parameters between the success group and failure group

\begin{tabular}{lllll}
\hline & Total & Success & Failure & $p$ value \\
& $n=173$ & $n=162$ & $n=11$ & \\
\hline Female, $n(\%)$ & $59(34.1)$ & $55(34.0)$ & $4(36.4)$ & $0.696^{*}$ \\
Age (years) & $68.2 \pm 12.8$ & $68.2 \pm 12.9$ & $69.3 \pm 11.7$ & 0.854 \\
APACHE II score & $17.6 \pm 5.7$ & $17.2 \pm 5.3$ & $23.4 \pm 8.7$ & 0.015 \\
BMI & $23.9 \pm 4.2$ & $24.1 \pm 4.2$ & $22.1 \pm 3.8$ & 0.075 \\
HR (bpm) & $77 \pm 13.5$ & $76.3 \pm 13.1$ & $87.1 \pm 15.6$ & 0.018 \\
RR (/min) & $16.1 \pm 4.7$ & $15.7 \pm 4.1$ & $23.3 \pm 7.0$ & 0.000 \\
TV (mL) & $457.4 \pm 102.3$ & $461 \pm 98.8$ & $405.4 \pm 140.6$ & 0.031 \\
RSBI & $38.4 \pm 18.3$ & $36.6 \pm 15.7$ & $64.3 \pm 31.8$ & 0.002 \\
PEEP (cmH2O) & $6.1 \pm 1.4$ & $6.2 \pm 1.3$ & $5.3 \pm 2.4$ & 0.065 \\
SpO2 (\%) & $99.2 \pm 1.0$ & $99.2 \pm 0.98$ & $98.6 \pm 1.4$ & 0.076 \\
EtCO2 (mmHg) & $39.3 \pm 5.2$ & $39.4 \pm 4.8$ & $37.8 \pm 9.3$ & 0.828 \\
LTC (mL/cmH2O) & $70.1 \pm 23.6$ & $71.9 \pm 23.0$ & $43.3 \pm 14.6$ & $<0.0001$ \\
\hline
\end{tabular}

Mann-Whitney $U$ Test was applied. *Fischer's exact test was applied for the comparison of ratios. From age to LTC, data were expressed as mean \pm standard deviation

APACHE II score Acute Physiology and Chronic Health Evaluation II score, BMI body mass index, $H R$ heart rate, $R R$ respiratory rate, $T V$ tidal volume, $R S B I$ rapid shallow breathing index, $P E E P$ positive end-expiratory pressure, $\mathrm{SPO} 2$ arterial oxygen saturation, EtCO2 end-tidal carbon dioxide, LTC lung-thorax compliance specificity is desirable, which indicates the usefulness of LTC as a predictor of extubation failure (Table 4). The sensitivity, specificity, and success rate of extubation were estimated at the different cutoff points for LTC. At a cutoff of 60 , the estimated specificity was greater than 0.9 , and the success rate was $96 \%$. However, at a cutoff of 50 , the estimated specificity was 0.636 , and the success rate was $90 \%$. LTC under 50-60 could indicate an increased probability of extubation failure in the SICU (Table 5).

Risk factors for extubation failure are known and include an RSBI greater than 100 [39-42], a $\mathrm{PaO}_{2}$ to $\mathrm{FiO}_{2}$ ratio less than $200 \mathrm{mmHg}$ [40], $\mathrm{PaCO}_{2}$ greater than $44 \mathrm{mmHg}$ during the SBT [43], and others [3, 11, 14, 15, 39-49]. In this study, vascular surgery was also a risk factor. In addition, WOB showed a significant difference between success group $(0.76 \pm 0.26)$ and failure group $(0.99 \pm 0.41)$. WOB is calculated using the following formula based on LTC: $\mathrm{WOB}=\mathrm{TV} / \mathrm{LTC}+($ inspiratory flow velocity $) \times($ resistance of the respiratory tract). The normal range of WOB is $0.3-0.7 \mathrm{~J} / \mathrm{L}$. The range is narrow, and it is more difficult to judge for determining extubation compared with LTC. In contract, LTC measured during the SBT is a candidate factor for extubation assessment because it is simple and accurate.

We adopted strict criteria in the SBT process because most of the subjects were operable patients and did not have severe respiratory complications. This may be the reason why the failure rate of our study (6.4\%) was lower 


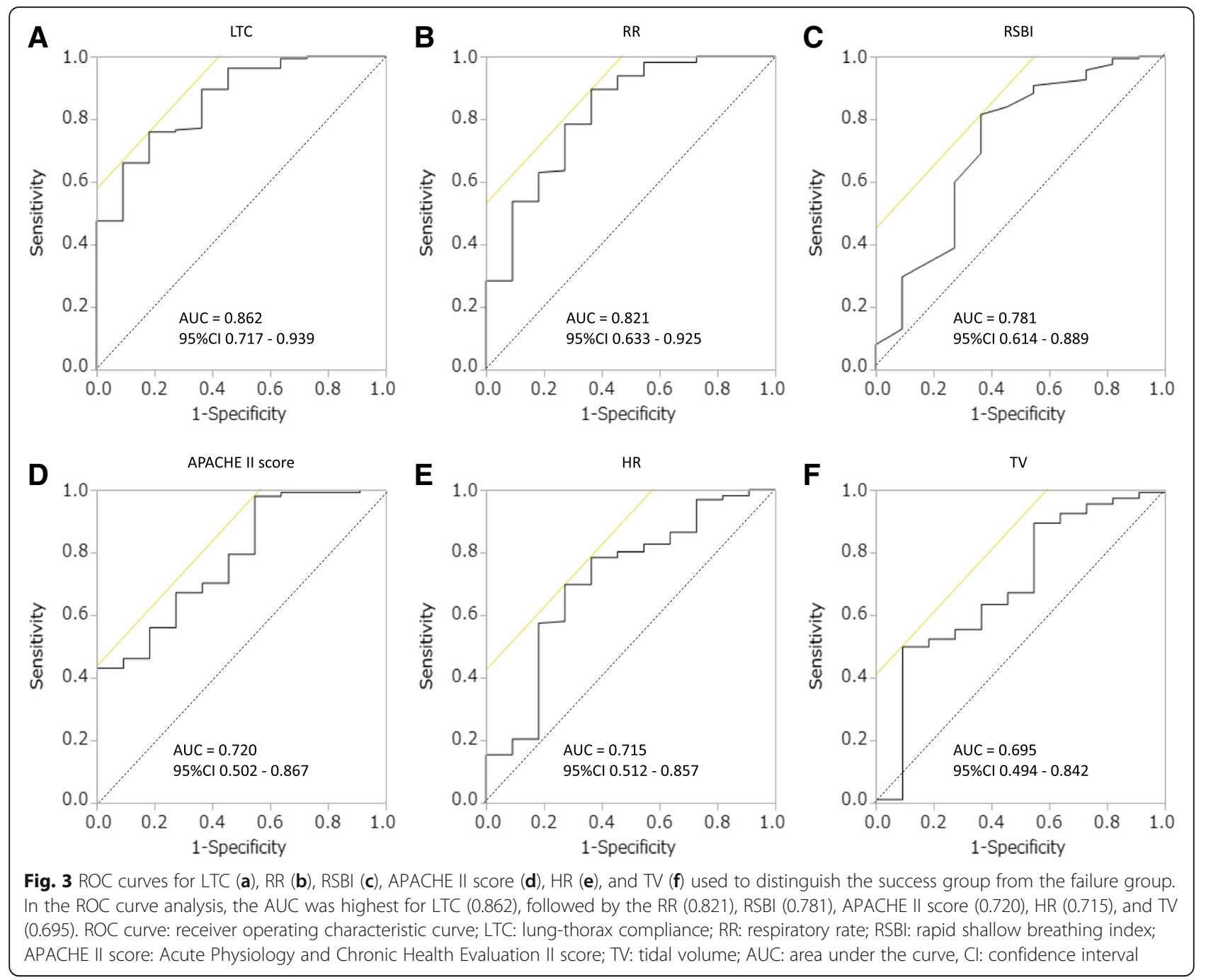

than those of previous reports (11-19\%) [1-4, 10-15]. The APACHE II score, HR, RR, TV, and RSBI were significantly different between the two groups even though all subjects met the SBT process criteria. These parameters were recorded as the average of the last $30 \mathrm{~min}$ of the observation period. Furthermore, the sensitivities of the RR, RSBI, APACHE II score, and HR were 0.895, $0.982,0.815$, and 0.698 , respectively, and the specificities were $0.636,0.455,0.636$, and 0.727 , respectively. The averages of the RR, RSBI, APACHE II score, or HR in
Table 4 Sensitivity and specificity at the cutoff of the highest Youden index

\begin{tabular}{llll}
\hline & Cutoff & Sensitivity & Specificity \\
\hline LTC $(\mathrm{mL} / \mathrm{cmH} 2 \mathrm{O})$ & 54 & 0.759 & 0.818 \\
$\mathrm{RR}(/ \mathrm{min})$ & 21 & 0.895 & 0.636 \\
$\mathrm{RSBI}$ & 72 & 0.982 & 0.455 \\
APACHE II & 21 & 0.815 & 0.636 \\
HR (bpm) & 81 & 0.698 & 0.727 \\
TV (mL) & 451 & 0.500 & 0.909
\end{tabular}

Youden index $=$ sensitivity + specificity -1

LTC lung-thorax compliance, $R R$ respiratory rate, $R S B I$ rapid shallow breathing index, APACHE II score Acute Physiology and Chronic Health Evaluation II score, $H R$ heart rate, $T V$ tidal volume
Table 5 Estimates of sensitivity, specificity, and success rate at several LTC cutoffs

\begin{tabular}{llll}
\hline Cutoff & Sensitivity & Specificity & Success rate (\%) \\
\hline 35 & 0.994 & 0.364 & 66 \\
40 & 0.944 & 0.546 & 77 \\
45 & 0.895 & 0.636 & 84 \\
50 & 0.840 & 0.636 & 90 \\
55 & 0.753 & 0.818 & 94 \\
60 & 0.654 & 0.909 & 96 \\
65 & 0.562 & 0.909 & 98 \\
70 & 0.488 & 0.909 & 99
\end{tabular}

LTC lung-thorax compliance 
the last $30 \mathrm{~min}$ of the observation period might be a predictor of extubation failure even when patients meet the SBT process criteria.

During the SBT process, five patients were excluded because they underwent a tracheostomy instead of extubation. The averages of the LTC, RR, RSBI, APACHE II score, and $\mathrm{HR}$ in these patients were 45.3, 22.9, 79.7, 18.8, and 75.4, respectively. All data indicated that patients in the failure group were in a worse condition than those in the success group. The results of the analysis were not different even with the inclusion of these patients.

According to Sandy et al., no difference was observed in the rate of extubation failure, duration of mechanical ventilation, or ICU and hospital stays among the SBT using PAV, T-tube, and PSV [50]. Bosma et al. revealed that the SBT using PAV was superior to PSV regarding the duration of mechanical ventilation or ICU stays [51]. Their results suggested that the PAV mode was a valid alternative for use in an SBT. Because PAV shows good synchronization with patients' spontaneous breathing [23-25, 51], an SBT can be performed when the sedative drugs are reduced, which may allow more accurate measurement of LTC. Moreover, in the PAV mode, LTC can be measured continuously. As a problem of PAV, patients with interstitial pneumonia and ARDS are over-ventilated because the inspiratory flow is fast as a result of restrictive disorders, but the inspiratory time and TV are limited. In patients with severe chronic obstructive pulmonary disease (COPD) and ICU-acquired weakness (ICUAW) [52], respiratory muscle fatigue lowers the work of breathing and inspiratory flow. Ventilation becomes insufficient, and excess $\mathrm{CO}_{2}$ leads to hypercapnia. Conducting an SBT using the PAV mode in these patients with severe respiratory failure is difficult. However, short-term use of PAV is possible for LTC measurement. Further studies on the effectiveness of LTC measurement for patients with severe respiratory disease are necessary.

This study has several limitations. First, the study was conducted in a single center with a small sample size. Therefore, a generalization of the results may not be possible. Second, most of the subjects were surgical patients because the study was conducted in the SICU; few patients had serious respiratory diseases. However, the number of subjects in each group provided sufficient power for adequate statistical calculations, and the study was conducted in a single SICU, resulting in less heterogeneity in patient management and monitoring. Third, because the LTC data were indicated on the monitor of the ventilator, intensivists could view the data. However, the influence of this on our study was low because this study was designed as a retrospective cohort study.

\section{Conclusion}

LTC measured during an SBT is a potential indicator of extubation failure in postoperative patients. Even in patients who met the strict SBT process criteria, the average RR, RSBI, APACHE II score, and HR in the last $30 \mathrm{~min}$ of the observation period might be the predictors of extubation failure. Further studies are necessary to determine the efficacy of this process for patients with severe respiratory disease.

\begin{abstract}
Abbreviations
APACHE II score: Acute Physiology and Chronic Health Evaluation II score: ARDS: Acute respiratory distress syndrome; AUC: Area under the curve; BMI: Body mass index; CNS: Central nervous system; COPD: Chronic obstructive pulmonary disease; $\mathrm{EtCO}_{2}$ : End-tidal carbon dioxide; $\mathrm{FiO}_{2}$ : Inspired oxygen fraction; HFNC: High-flow nasal cannula; HR: Heart rate; IV-PCA: Intravenous patient-controlled analgesia; LTC: Lung-thorax compliance; NPPV: Non-invasive positive-pressure ventilation; NSAIDs: Nonsteroidal anti-inflammatory drugs; $\mathrm{PaCO}_{2}$ : Partial pressure of arterial carbon dioxide; $\mathrm{PaO}_{2}$ : Partial pressure of arterial oxygen; PAV: Proportional assist ventilation; PEEP: Positive end-expiratory pressure; pH: Power of hydrogen; PNB: Peripheral nerve block; RASS: Richmond Agitation-Sedation Scale; ROC curve: Receiver operating characteristic curve; RR: Respiratory rate; RSBI: Rapid shallow breathing index; SBT: Spontaneous breathing trial; SICU: Surgical intensive care unit; SIMV: Synchronized intermittent mandatory ventilation; $\mathrm{SpO}_{2}$ : Arterial oxygen saturation; TV: Tidal volume; WOB: Work of breathing
\end{abstract}

\section{Acknowledgements \\ We gratefully acknowledge the work of the members of our laboratory.}

\section{Availability of data and materials}

The datasets used and/or analyzed during the current study are available from the corresponding author on reasonable request.

\section{Authors' contributions}

YO contributed to the study conception, research plan creation, data collection, data analysis, and manuscript preparation. TA and SB contributed to the data collection, data analysis confirmation, and chart creation. HS contributed to the data collection, data analysis confirmation, and manuscript preparation. KK contributed to the data collection, manuscript preparation, and chart creation. TY and GS contributed to the data collection, data analysis confirmation, and manuscript proofreading. TH contributed to the research plan creation, data collection, data analysis confirmation, and manuscript proofreading. All authors read and approved the final manuscript.

Ethics approval and consent to participate

This study was approved by the Ethical Review Board, Faculty of Medicine, Kagawa University (Heisei 29-049). The consent form was acquired when anesthesia was explained or at the admission to the intensive care unit.

\section{Consent for publication}

The consent form was acquired at the time of the explanation of anesthesia or admission to the intensive care units.

\section{Competing interests}

The authors declare that they have no competing interests.

\section{Publisher's Note}

Springer Nature remains neutral with regard to jurisdictional claims in published maps and institutional affiliations.

\section{Author details}

'Department of Anesthesiology, Faculty of Medicine, Kagawa University, 1750-1 Ikenobe, Miki-Cho, Kagawa 761-0793, Japan. ${ }^{2}$ Department of Hygiene, Faculty of Medicine, Kagawa University, Miki-Cho, Kagawa, Japan.

${ }^{3}$ Department of Public Health, Faculty of Medicine, Kagawa University, 1750-1

Ikenobe, Miki-Cho, Kagawa 761-0793, Japan. ${ }^{4}$ Department of Health and Sports Science, Kawasaki University of Medical Welfare, 228 Matushima, Kurasiki-shi, Okayama 701-0193, Japan. 


\section{Received: 17 April 2018 Accepted: 18 July 2018}

\section{Published online: 31 July 2018}

\section{References}

1. Frutos-Vivar F, Esteban A, Apezteguia C, Gonzalez M, Arabi Y, Restrepo Ml, Gordo F, Santos C, Alhashemi JA, Perez F, et al. Outcome of reintubated patients after scheduled extubation. J Crit Care. 2011;26(5):502-9.

2. Thille AW, Cortes-Puch I, Esteban A. Weaning from the ventilator and extubation in ICU. Curr Opin Crit Care. 2013:19(1):57-64.

3. Thille AW, Harrois A, Schortgen F, Brun-Buisson C, Brochard L. Outcomes of extubation failure in medical intensive care unit patients. Crit Care Med. 2011;39(12):2612-8.

4. Thille AW, Richard JC, Brochard L. The decision to extubate in the intensive care unit. Am J Respir Crit Care Med. 2013;187(12):1294-302.

5. Esteban A, Anzueto A, Frutos F, et al. Characteristics and outcomes in adult patients receiving mechanical ventilation: a 28-day international study. JAMA. 2002;287(3):345-55.

6. Torres A, Gatell JM, Aznar E, El-Ebiary M, de la Bellacasa JP, González J, Ferrer $M$, Rodriguez-Roisin R. Re-intubation increases the risk of nosocomial pneumonia in patients needing mechanical ventilation. Am J Respir Crit Care Med. 1995;152(1):137-41.

7. Boles JM, Bion J, Connors A, Herridge M, Marsh B, Melot C, Pearl R, Silverman H, Stanchina M, Vieillard-Baron A, et al. Weaning from mechanical ventilation. Eur Respir J. 2007;29(5):1033-56.

8. Ely EW, Baker AM, Dunagan DP, Burke HL, Smith AC, Kelly PT, Johnson MM, Browder RW, Bowton DL, Haponik EF. Effect on the duration of mechanical ventilation of identifying patients capable of breathing spontaneously. N Engl J Med. 1996;335(25):1864-9.

9. Robertson TE, Mann HJ, Hyzy R, Rogers A, Douglas I, Waxman AB, Weinert C, Alapat P, Guntupalli KK, Buchman TG. Multicenter implementation of a consensus-developed, evidence-based, spontaneous breathing trial protocol*. Crit Care Med. 2008;36(10):2753-62.

10. Burns KEA, Soliman I, Adhikari NKJ, Zwein A, Wong JTY, Gomez-Builes C, Pellegrini JA, Chen L, Rittayamai N, Sklar M, et al. Trials directly comparing alternative spontaneous breathing trial techniques: a systematic review and meta-analysis. Crit Care. 2017;21(1):127.

11. Epstein SK, Ciubotaru RL, Wong JB. Effect of failed extubation on the outcome of mechanical ventilation. Chest. 1997;112(1):186-92.

12. Esteban A, Alía I, Tobin MJ, Gil A, Gordo F, Vallverdú I, Blanch L, Bonet A, Vázquez A, Pablo RD, et al. Effect of spontaneous breathing trial duration on outcome of attempts to discontinue mechanical ventilation. Am J Respir Crit Care Med. 1999;159(2):512-8.

13. Esteban A, Alía I, Gordo F, Fernández R, Solsona JF, Vallverdú I, Macías S, Allegue JM, Blanco J, Carriedo D, et al. Extubation outcome after spontaneous breathing trials with T-tube or pressure support ventilation. Am J Respir Crit Care Med. 1997:156(2):459-65.

14. Epstein SK. Noninvasive ventilation to shorten the duration of mechanical ventilation. Respir Care. 2009:54:198-211.

15. Miu T, Joffe AM, Yanez ND, Khandelwal N, Dagal AH, Deem S, Treggiari MM. Predictors of reintubation in critically ill patients. Respir Care. 2014;59(2):178-85.

16. Younes M, Webster K, Kun J, Roberts D, Masiowski B. A method for measuring passive elastance during proportional assist ventilation. Am J Respir Crit Care Med. 2001;164(1):50-60.

17. Ranieri VM, Eissa NT, Corbeil C, Chassé M, Braidy J, Matar N, Milic-Emili J. Effects of positive end-expiratory pressure on alveolar recruitment and gas exchange in patients with the adult respiratory distress syndrome. Am Rev Respir Dis. 1991;144(3_pt_1):544-51.

18. Ranieri VM, Giuliani R, Fiore T, Dambrosio M, Milic-Emili J. Volume-pressure curve of the respiratory system predicts effects of PEEP in ARDS: "Occlusion" versus "constant flow" technique. Am J Respir Crit Care Med. 1994;149(1):19-27.

19. Amato MB, Barbas CS, Medeiros DM, Schettino GD, Filho GL, Kairalla RA Deheinzelin D, Morais C, Fernandes EO, Takagaki TY. Beneficial effects of the "open lung approach" with low distending pressures in acute respiratory distress syndrome. A prospective randomized study on mechanical ventilation. Am J Respir Crit Care Med. 1995;152(6):1835-46.

20. Tobin MJ. Respiratory monitoring in the intensive care unit. Am Rev Respir Dis. 1988;138(6):1625-42.

21. Yokoyama $\mathrm{H}$, Kondou M, Morio Y, Hiraki K. Usefulness of pulmonary compliance determination in patients undergoing artifical respiration: relationship of pulmonary compliance to tidal volume and weaning from mechanical ventilation. Rigakuryoho Kagaku. 2007;22(3):373-8.
22. Younes $M$, Riddle W, Polacheck J. A model for the relation between respiratory neural and mechanical outputs. III. Validation. J Appl Physiol. 1981;51(4):990-1001.

23. Grasso S, Puntillo F, Mascia L, Ancona G, Fiore T, Bruno F, Slutsky AS, Ranieri VM. Compensation for increase in respiratory workload during mechanical ventilation. Am J Respir Crit Care Med. 2000;161(3):819-26.

24. Mitrouska J, Xirouchaki N, Patakas D, Siafakas N, Georgopoulos D. Effects of chemical feedback on respiratory motor and ventilatory output during different modes of assisted mechanical ventilation. Eur Respir J. 1999;13:873-82.

25. Ranieri VM, Giuliani R, Mascia L, Grasso S, Petruzzelli V, Puntillo N, Perchiazzi G, Fiore T, Brienza A. Patient-ventilator interaction during acute hypercapnia: pressuresupport vs. proportional-assist ventilation. J Appl Physiol. 1996;81(1):426-36.

26. Xirouchaki N, Kondili E, Klimathianaki M, Georgopoulos D. Is proportionalassist ventilation with load-adjustable gain factors a user-friendly mode? Intensive Care Med. 2009:35(9):1599-603.

27. Girard TD, Kress JP, Fuchs BD, Thomason JWW, Schweickert WD, Pun BT, Taichman DB, Dunn JG, Pohlman AS, Kinniry PA, et al. Efficacy and safety of a paired sedation and ventilator weaning protocol for mechanically ventilated patients in intensive care (awakening and breathing controlled trial): a randomised controlled trial. Lancet. 2008;371(9607):126-34.

28. Kress JP, Pohlman AS, O'Connor MF, Hall JB. Daily interruption of sedative infusions in critically ill patients undergoing mechanical ventilation. N Engl J Med. 2000;342(20):1471-7.

29. Treggiari MM, Romand J-A, Yanez ND, Deem SA, Goldberg J, Hudson L, Heidegger C-P, Weiss NS. Randomized trial of light versus deep sedation on mental health after critical illness*. Crit Care Med. 2009:37(9):2527-34.

30. Sessler CN, Gosnell MS, Grap MJ, Brophy GM, O'Neal PV, Keane KA, Tesoro EP, Elswick RK. The Richmond Agitation-Sedation Scale. Am J Respir Crit Care Med. 2002;166(10):1338-44.

31. Perren A, Domenighetti G, Mauri S, Genini F, Vizzardi N. Protocol-directed weaning from mechanical ventilation: clinical outcome in patients randomized for a 30-min or 120-min trial with pressure support ventilation. Intensive Care Med. 2002;28(8):1058-63.

32. Maclntyre NR. Evidence-based guidelines for weaning and discontinuing ventilatory support: a collective task force facilitated by the American College of Chest Physicians; the American Association for Respiratory Care; and the American College of Critical Care Medicine. Chest. 2001;120(6, Supplement):375S-95S.

33. Keeping A. Early versus late tracheostomy for critically ill patients: a clinical evidence synopsis of a recent Cochrane Review. Canadian Journal of Respiratory Therapy: CJRT = Revue Canadienne de la Thérapie Respiratoire : RCTR. 2016;52(1):27-8.

34. Knaus WA, Draper EA, Wagner DP, Zimmerman JE. APACHE II: a severity of disease classification system. Crit Care Med. 1985;13(10):818-29.

35. Haenel JB, Johnson JL. Chapter 21 - mechanical ventilation in critical illness. In: Anesthesia secrets. 4th ed. Philadelphia: Mosby; 2011. p. 149-56.

36. Suter PM, Fairley HB, Isenberg MD. Effect of tidal volume and positive endexpiratory pressure on compliance during mechanical ventilation. Chest. 1978:73(2):158-62.

37. Nassar BS, Collett ND, Schmidt GA. The flow-time waveform predicts respiratory system resistance and compliance. J Crit Care. 2012;27(4):418.

38. Youden WJ. Index for rating diagnostic tests. Cancer. 1950;3(1):32-5.

39. Frutos-Vivar F, Ferguson ND, Esteban A, Epstein SK, Arabi Y, Apezteguía C, González M, Hill NS, Nava S, D'Empaire G, et al. Risk factors for extubation failure in patients following a successful spontaneous breathing trial. Chest. 2006;130(6):1664-71.

40. Namen AM, Ely EW, Tatter SB, Case LD, Lucia MA, Smith A, Landry S, Wilson JA, Glazier SS, Branch CL, et al. Predictors of successful extubation in neurosurgical patients. Am J Respir Crit Care Med. 2001;163(3):658-64.

41. Smina M, Salam A, Khamiees M, Gada P, Amoateng-Adjepong Y, Manthous CA. Cough peak flows and extubation outcomes. Chest. 2003:124(1):262-8.

42. Thille AW, Boissier F, Ben Ghezala H, Razazi K, Mekontso-Dessap A, BrunBuisson C. Risk factors for and prediction by caregivers of extubation failure in ICU patients: a prospective study. Crit Care Med. 2015;43(3):613-20.

43. Mokhlesi B, Tulaimat A, Gluckman TJ, Wang Y, Evans AT, Corbridge TC Predicting extubation failure after successful completion of a spontaneous breathing trial. Respir Care. 2007:52:1710-7.

44. Chien J-Y, Lin M-S, Huang Y-CT, Chien Y-F, Yu C-J, Yang P-C. Changes in Btype natriuretic peptide improve weaning outcome predicted by spontaneous breathing trial. Crit Care Med. 2008;36(5):1421-6. 
45. Lemaire F, Teboul JL, Cinotti L, Giotto G, Abrouk F, Steg G, Macquin-Mavier I, Zapol WM. Acute left ventricular dysfunction during unsuccessful weaning from mechanical ventilation. Anesthesiology. 1988;69(2):171-9.

46. Su W-L, Chen Y-H, Chen C-W, Yang S-H, Su C-L, Perng W-C, Wu C-P, Chen J$\mathrm{H}$. Involuntary cough strength and extubation outcomes for patients in an ICU. Chest. 2010;137(4):777-82.

47. Teixeira C, da Silva NB, Savi A, Vieira SRR, Nasi LA, Friedman G, Oliveira RP, Cremonese RV, Tonietto TF, Bressel MAB, et al. Central venous saturation is a predictor of reintubation in difficult-to-wean patients*. Crit Care Med. 2010; 38(2):491-6.

48. Tillquist MN, Gabriel RA, Dutton RP, Urman RD. Incidence and risk factors for early postoperative reintubations. J Clin Anesth. 2016;31:80-9.

49. Vallverdú I, Calaf N, Subirana M, Net A, Benito S, Mancebo J. Clinical characteristics, respiratory functional parameters, and outcome of a twohour T-piece trial in patients weaning from mechanical ventilation. Am J Respir Crit Care Med. 1998;158(6):1855-62.

50. Teixeira SN, Osaku EF, Costa CR, Toccolini BF, Costa NL, Candia MF, Leite MA, Jorge AC, Duarte PA. Comparison of proportional assist ventilation plus, T-tube ventilation, and pressure support ventilation as spontaneous breathing trials for extubation: a randomized study. Respir Care. 2015;60(11): 1527-35.

51. Bosma KJ, Read BA, Bahrgard Nikoo MJ, Jones PM, Priestap FA, Lewis JF. A pilot randomized trial comparing weaning from mechanical ventilation on pressure support versus proportional assist ventilation. Crit Care Med. 2016; 44(6):1098-108.

52. Levine S, Nguyen T, Taylor N, Friscia ME, Friscia ME, Budak MT, Rothenberg P, Zhu J, Sachdeva R, Sonnad S, Kaiser LR, Rubinstein NA, et al. Rapid disuse atrophy of diaphragm fibers in mechanically ventilated humans. N Engl J Med. 2008;358(13):1327-35.

Ready to submit your research? Choose BMC and benefit from:

- fast, convenient online submission

- thorough peer review by experienced researchers in your field

- rapid publication on acceptance

- support for research data, including large and complex data types

- gold Open Access which fosters wider collaboration and increased citations

- maximum visibility for your research: over $100 \mathrm{M}$ website views per year

At $\mathrm{BMC}$, research is always in progress.

Learn more biomedcentral.com/submissions 